upon the floodplain materials of the river.

Deposits laid down in the period 1845-1886 had the highest concentrations of lead (1,500 p.p.m. dry soil). Following this, in the zone 1886-1904, values dropped to 1,011 p.p.m.; the fall could reflect the 1876 Act of Parliament requiring the cleansing of mine effluents. Mining ceased at about 1900 and the subsequent zones have lower concentrations of lead: 1904-1951, 785 p.p.m.; 1951-1971, 503 p.p.m.; 1972, 368 p.p.m.

These data show that, despite the reworking of older deposits during the formation of meanders, the lead contents of alluvial soils do reflect the contemporary conditions of lead pollution in the river. This technique could be used for the historical studies of alluvial pedogenesis in similar situations but where precise mapping is unavailable. The accumulation of heavy metals in alluvium is also a salutary reminder that the precise drainage conditions which make these soils the recipients of leached and eroded plant nutrients, producing high fertility, also result in the concentration of the toxic materials eroded from the catchment. The advisability of using such alluvial soils for arable agriculture or grazing will depend on conditions of river pollution during the period in which accumulation of the substrate took place.

\section{Evaporation and gas exchange in nature}

from P. S. Liss

THE evaporation of water from natural water bodies is largely controlled by aerodynamic processes in the air above the water surface. By contrast, exchange of sparingly soluble gases, such as oxygen, carbon dioxide, nitrogen and the inert gases, across air-water interfaces in the environment is almost entirely dependent on the degree of turbulence in the liquid phase. This fundamental difference leads to very different approaches in the study of evaporation and gas exchange in nature. For instance in order to describe evaporation, sophisticated mathematical treatments of atmospheric turbulence are necessary, whereas it seems that simple laminar models can go a long way towards elucidating airwater exchange rates for dissolved gases.

In order for water molecules to evaporate from a water surface they must have sufficient energy to escape from the liquid. Furthermore, the aerodynamic regime in the air above the interface must be such that the water molecule is prevented from con- densing back onto the surface. At the 22nd Bat-Sheva seminar, which this year took for its subject "Mechanism of Evaporation and Gas Exchange in Nature" and was held from June 16-30 at the Weizmann Institute of Science, Rehovot, W. H. Brutsaert (Cornell University) presented a detailed mathematical treatment of evaporation and showed how semi-empirical theories of atmospheric turbulence can be used to help solve the differential equations involved. These lectures were complemented by those of C. B. Tanner (University of Wisconsin) who reviewed the practical methods so far used to measure evaporation rates over land surfaces. He illustrated the importance of such studies by pointing out that evaporation represents on average $70 \%$ of the total outflow from catchments in the United States. In arid regions the figure may rise as high as $95 \%$. The best estimates of evaporation seem to be those based on measurements of the energetics of the process. especially when these methods are locally calibrated. G. Stanhill (Volcani Center, Bet-Dagan) led a discussion on the various methods of preventing evaporation from water bodies and plants. For open waters, monolayers have been tried, but it is hard to maintain a continuous film at the surface when there is any appreciable wind. Pumping cold water from the bottom of the lake to decrease the temperature of the surface and so reduce evaporation is a novel technique which deserves attention. There has been some success in laboratory experiments in which plant leaves are sprayed with a chemical in order to increase their stomatal resistance and so reduce evapo-transpiration, but such techniques do not seem to work well when applied to crops in the field.

A laminar layer model has been used by W. S. Broecker (Lamont Geological Observatory) to characterise exchange of sparingly soluble gases across the air-sea interface. From measurements of $\mathrm{Rn}-222$ and its parent Ra-226 near the water surface, it is possible to calculate the thickness of the laminar layer at the sea surface. From such measurements, made as part of the GEOSECS programme in the Atlantic and the Pacific, there are now reasonable average values for gas exchange rates in the major oceans. These values can be used to calculate the fluxes of many atmospheric trace constituents (both natural and anthropogenic) across the sea surface. S. Emerson (Swiss Federal Institute for Water Protection) showed how similar techniques have been applied in lakes to obtain rates of $\mathrm{CO}_{2}$ transfer across the interface. His results indicate that, despite reports to the contrary, dissolved carbon is unlikely to be a limit- ing factor in algal growth in lakes, because $\mathrm{CO}_{2}$ can transfer from the atmosphere to the water at a rate fast enough to supply the carbon required for phytoplankton growth.

The molecular structure of liquid water was considered by $R$. A. Horne (Arthur D. Little Inc.). Of especial importance in the context of the seminar was his analysis of how the properties of the very surface layers of water molecules (vicinal water) differ from those of the bulk liquid. Vicinal water seems to differ from the bulk fluid over a wide range of physical (freezing point, viscosity, thermal expansion) and chemical (solubilities of ionic and non-polar solutes) properties, but its thickness is still a subject of much debate.

\section{Thermal disruption in the asthenosphere}

from Peter J. Smith

Geomagnetism Correspondent

THE possibility that nonlinear viscous heating could produce thermal runaways in the Earth's interior was first recognised by Gruntfest (Trans Soc. Rheol., 7, 195; 1963) who used the heat equations to show that, for one-dimensional plane viscous flow under constant stress in a slab, the temperature and strain rate may become arbitrarily large in finite time under adiabatic or near-adiabatic conditions. Many of the ideas initiated by Gruntfest were then later applied by Shaw (see, for example, J. Petrol., 10, 510; 1969) and Shaw et al. (Bull. geol. Soc. Am., 82, 869; 1971) to specific geological situations such as the rheology of basalt, the relation between Earth tides and magmatism in the Sierra Nevada, and Hawaiian volcanism. More recently, Fujii and Uyeda have been quoted as having used the ideas of both Gruntfest and Shaw to explain the size of intrusive dykes and the eruptive history of volcanoes.

But talk of magmatism, volcanism and viscous flow leads naturally to deeper thoughts about the asthenosphere in mind that $O$. L. Anderson and Perkins (J. geophys. Res., 79, 2136 ; 1974) have been looking again, but in a rather different way, at the possibility and implications of thermal runaways in the Earth. They begin by drawing attention to the fact that the heat flow equation applicable to onedimensional viscous flow at constant stress is the same one-dimensional equation as that used to describe thermal explosions in solids, and then go on to explore the consequences of this connection between two apparently quite different situations. The fact is that the common equation implies fea- 